\title{
Factors influencing fertility outcome after ectopic pregnancy: a descriptive observational study
}

\author{
Veena $\mathbf{K S}^{1 *}$, Vidyameena $\mathbf{R}^{2}$, Rupavani Kollipaka ${ }^{3}$
}

\author{
${ }^{1}$ Department of Obstetrics, Sri Manukula Vinayagar Medical College, Puducherry, India \\ ${ }^{2}$ Government General Hospital, Karaikal, Puducherry, India \\ ${ }^{3}$ Assistant Professor, Indira Gandhi Medical College, Puducherry, India
}

Received: 20 April 2015

Revised: 06 May 2015

Accepted: 09 May 2015

\author{
*Correspondence: \\ Dr. Veena KS, \\ E-mail: ssykid2003@yahoo.co.uk
}

Copyright: () the author(s), publisher and licensee Medip Academy. This is an open-access article distributed under the terms of the Creative Commons Attribution Non-Commercial License, which permits unrestricted non-commercial use, distribution, and reproduction in any medium, provided the original work is properly cited.

\begin{abstract}
Background: Ectopic pregnancy is the commonest gynecological emergencies. If not treated timely, threatens the life but also places major morbidity on future fertility. This study performed to determine the future pregnancy outcomes following surgical management of ectopic pregnancy and factors influencing the outcome.

Methods: Prospective observational study conducted at Tertiary Hospital. Records of patients with ectopic pregnancy between 2005 to 2010 traced, interviewed about fertility outcomes and the risk factors using a structured questionnaire. Patients followed for 3 years from index ectopic pregnancy. The main outcome measure was the occurrence of intrauterine pregnancy or ectopic pregnancy at 3 years of follow-up after the index ectopic pregnancy. Results: 64 patients with primary ectopic formed the basis of the study. $84.37 \%$ of patients undergone radical surgery (salpingectomy) and $15.62 \%$ forming the conservative group (Salpingotomy/milking) were included. In 3 years follow up, $40 \%$ of conservative group and $59 \%$ of radical group had intrauterine pregnancy. $30 \%$ in conservative group and $46 \%$ of radical group had term delivery. $20 \%$ of conservative group and $18.51 \%$ in radical group had repeated ectopic. Incidence of term delivery in patients with the past history of sub fertility was $25 \%$ and without subfertility $46 \% .17 \%$ with tubal pathology and $63 \%$ with normal tube had term pregnancy. $37 \%$ aged more than 30 years and $44.64 \%$ aged less than 30 years had term pregnancy.

Conclusions: Subfertility, tubal pathology and age will influence on future fertility outcome following ectopic pregnancy. Radical or conservative surgery does not have influence on future pregnancy outcome.
\end{abstract}

Keywords: Ectopic pregnancy, Subfertility

\section{INTRODUCTION}

Ectopic pregnancy is the commonest gynecological emergencies. If not treated timely, places major morbidity upon future fertility and family. Progress in terms of early diagnosis and medical management has taken place in developed countries, shifting the clinician's concern away from immediate health of the women towards preserving her subsequent fertility. However, in developing countries, main modality of treatment for ectopic pregnancy has been laparotomy and surgery hampering fertility as most of the patients. ${ }^{1}$

Several risk factors have been identified for ectopic pregnancy like pelvic inflammatory disease especially with Chlamydia trachomatis, tubal surgeries, use of intrauterine devices, multiple sex partners, smoking, induction of ovulation by clomiphene, previous pelvic surgeries and age. ${ }^{2}$ 
The purpose of this study was to evaluate the reproductive performance such as term pregnancy rate and repeat ectopic pregnancy rate after conservative or radical surgery for tubal pregnancy and to investigate whether age, subfertility or tubal pathology can influence the subsequent fertility.

\section{METHODS}

Prospective observational study conducted at Tertiary Hospital. Medical records of patients who were surgically managed for ectopic pregnancy between January 2005 to December 2010 were traced. They were called back to the hospital by phone calls explaining about the study and asking for their willingness to participate in the study. Women willing to participate were interviewed using a structured questionnaire.

The basic information collected from each woman included: Socioeconomic status, sexual, gynecological, reproductive and surgical history, use of contraception, ovulation induction prior to Ectopic Pregnancy. The characteristics of the index ectopic pregnancy such as age, parity, side, site, tubal rupture, surgical treatment and tubal pathology given are noted from respective Medical records. Any patient who was not intending to become pregnant and those who conceived with IVF were excluded from the analysis. Patients were classified into two groups. Radical surgery group comprised patients who undergone salpingectomy and conservative group comprising patients with salpingotomy or milking of tubes. Both the groups followed for period of 3 years from index ectopic pregnancy. During follow up visits all were enquired about their reproductive status. The main outcome measure was the occurrence of an intrauterine pregnancy or ectopic pregnancy during the follow up period.

\section{RESULTS}

Total number of deliveries conducted was 93384. As mentioned in Figure 1, a total of 64 patients with primary ectopic formed the study group. Incidence of EP was $0.2 \%$. Mean age of patients was 24 years (Range 19-40). Based on the type of surgery performed, conservative group comprised of 10 patients. Among them, 7 patients underwent milking of the tube and 3 patients underwent salpingotomy. Patients who underwent conservative procedures were followed up with $\beta \mathrm{HCG}$ and none of them required any further procedure. 'Radical group' comprised of 54 patients who underwent partial salpingectomy. $58 \%$ belonged to the low socio economic status and $42 \%$ of the sample was from a middle socioeconomic status. And none in high socio-economic status. $52 \%$ of the ectopic pregnancies occurred in the right tube and $48 \%$ in the left tube.

Considering the site of ectopic pregnancy, $97 \%$ of cases occurred in the fallopian tube and $3 \%$ in the ovary and rudimentary horn. Among tubal pregnancies $76 \%$ were ampullary and $14 \%$ were isthmal. Considering the presentation, $78.12 \%$ presented as ruptured ectopic pregnancy, $17.1 \%$ as tubal abortion and $4.68 \%$ presented at unruptured stage.

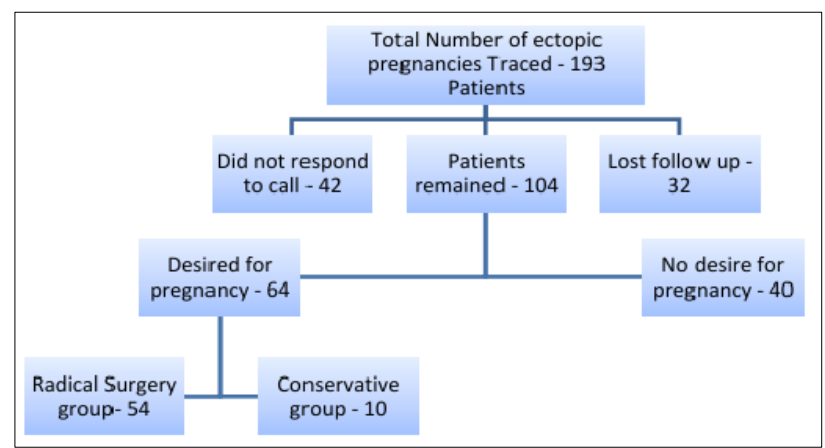

Figure 1: Total number of ectopic pregnancies traced.

Laparotomy was performed for all the patients. Among them $84.37 \%$ underwent Salpingectomy, $4.6 \%$ underwent Salpingotomy and milking in $10.90 \%$. None of the patients in conservative group had repeat laparotomy for persistent ectopic.

Baseline characters mentioned in Table 1. Tubal pathology was most common risk factor being $60 \%$ in conservative group and $39 \%$ in radical group. Majority of these patients had peri tubal adhesions and few patients had hydrosalphinx. Previous LSCS was second common risk factor in both groups. Subfertility was more common conservative group than in the radical group.

Table 1: Baseline characteristics and risk factors.

\begin{tabular}{|ll|l|}
\hline Parameter & $\begin{array}{l}\text { Conservative } \\
\text { group }(\mathbf{n = 1 0})\end{array}$ & $\begin{array}{l}\text { Radical group } \\
(\mathbf{n}=54)\end{array}$ \\
\hline Mean age (SD) (years) & $23(5 \%)$ & $23(6 \%)$ \\
\hline Nulliparity & $3(30 \%)$ & $12(22.2 \%)$ \\
\hline Previous tubal surgery & $1(10 \%)$ & $3(5.5 \%)$ \\
\hline Previous LSCS & $3(30 \%)$ & $24(44 \%)$ \\
\hline Previous PID & $2(20 \%)$ & $7(12.96 \%)$ \\
\hline $\begin{array}{l}\text { Homolateral tubal } \\
\text { pathology }\end{array}$ & $3(30 \%)$ & $11(20.37 \%)$ \\
\hline $\begin{array}{l}\text { Contralateral tubal } \\
\text { pathology }\end{array}$ & $3(30 \%)$ & $10(18.51 \%)$ \\
\hline Subfertility at time of EP & $2(20 \%)$ & $6(11.11 \%)$ \\
\hline
\end{tabular}

Table 2: Antecedent pregnancy outcome.

\begin{tabular}{|lll|} 
& $\begin{array}{l}\text { Conservative } \\
(\mathbf{n = 1 0})\end{array}$ & $\begin{array}{l}\text { Radical } \\
(\mathbf{n}=54)\end{array}$ \\
\hline Intrauterine & $4(40 \%)$ & $32(59.25 \%)$ \\
\hline Abortion & - & $3(5.5 \%)$ \\
\hline Term delivery & $3(30 \%)$ & $25(46.29 \%)$ \\
\hline $\begin{array}{l}\text { On-going } \\
\text { pregnancy }\end{array}$ & $1(10 \%)$ & $3(5.5 \%)$ \\
\hline Ectopic & $2(20 \%)$ & $10(18.51 \%)$ \\
\hline
\end{tabular}


Considering antecedent pregnancy outcome as mentioned in Table 2, Percentage of term delivery among both groups were comparable. Incidence of repeat ectopic pregnancy was same in both groups and was higher compared to overall incidence $(0.2 \%)$.

As mentioned in Table 3, intra uterine pregnancy percentage among patients with history of subfertility was comparable. But repeat ectopic pregnancy rate is tripled in patients with past history of subfertility. In patients aged more than 30 years occurrence of intra uterine pregnancy was $25 \%$ compared to $62 \%$ in patients with less than 30 years. Occurrence of repeat ectopic pregnancy in patients with tubal pathology was $39 \%$ compared to $2.77 \%$ in women with normal tubes.

Table 3: Effect of risk factors on outcome.

\begin{tabular}{|c|c|c|c|c|c|c|}
\hline \multicolumn{7}{|c|}{ Effect of risk factors on outcome } \\
\hline \multicolumn{4}{|c|}{ Abnormal tubal pathology $(n=28)$} & \multicolumn{3}{|c|}{ Normal tube $(n=36)$} \\
\hline Group & $\begin{array}{l}\text { Conservative } \\
(n=7)\end{array}$ & $\begin{array}{l}\text { Radical } \\
(n=21)\end{array}$ & $\begin{array}{l}\text { Total } \\
(n=28)\end{array}$ & $\begin{array}{l}\text { Conservative } \\
(\mathbf{n}=3)\end{array}$ & $\begin{array}{l}\text { Radical } \\
(n=33)\end{array}$ & $\begin{array}{l}\text { Total } \\
(n=36)\end{array}$ \\
\hline $\begin{array}{l}\text { Intrauterine } \\
\text { pregnancy }\end{array}$ & 1 & 5 & $6(21.42 \%)$ & 3 & 27 & $30(83.33 \%)$ \\
\hline $\begin{array}{l}\text { Ectopic } \\
\text { pregnancy }\end{array}$ & 2 & 9 & $11(39.28 \%)$ & 0 & 1 & $1(2.77 \%)$ \\
\hline \multicolumn{7}{|c|}{ Effect of subfertility } \\
\hline \multicolumn{4}{|c|}{ Past history of subfertility $(n=8)$} & \multicolumn{3}{|c|}{ No history of subfertility $(n=56)$} \\
\hline Group & $\begin{array}{l}\text { Conservative } \\
(n=2)\end{array}$ & $\begin{array}{l}\text { Radical } \\
(n=6)\end{array}$ & $\begin{array}{l}\text { Total } \\
(n=8)\end{array}$ & $\begin{array}{l}\text { Conservative } \\
(\mathrm{n}=8)\end{array}$ & $\begin{array}{l}\text { Radical } \\
(n=48)\end{array}$ & $\begin{array}{l}\text { Total } \\
(n=56)\end{array}$ \\
\hline $\begin{array}{l}\text { Intrauterine } \\
\text { pregnancy }\end{array}$ & 1 & 2 & $3(37.5 \%)$ & 3 & 30 & $33(58.92 \%)$ \\
\hline $\begin{array}{l}\text { Ectopic } \\
\text { pregnancy }\end{array}$ & 1 & 3 & $4(50 \%)$ & 1 & 7 & $8(14.28 \%)$ \\
\hline \multicolumn{7}{|l|}{ Effect of age } \\
\hline \multicolumn{4}{|l|}{ Age $>\mathbf{3 0}$} & \multicolumn{3}{|l|}{ Age $<30$} \\
\hline Group & $\begin{array}{l}\text { Conservative } \\
(n=2)\end{array}$ & $\begin{array}{l}\text { Radical } \\
(n=6)\end{array}$ & $\begin{array}{l}\text { Total } \\
(n=8)\end{array}$ & $\begin{array}{l}\text { Conservative } \\
(\mathrm{n}=8)\end{array}$ & $\begin{array}{l}\text { Radical } \\
(n=48)\end{array}$ & $\begin{array}{l}\text { Total } \\
(n=56)\end{array}$ \\
\hline $\begin{array}{l}\text { Intrauterine } \\
\text { pregnancy }\end{array}$ & - & 3 & $2(25 \%)$ & 4 & 30 & $34(62.70 \%)$ \\
\hline $\begin{array}{l}\text { Ectopic } \\
\text { pregnancy }\end{array}$ & 1 & 1 & $2(25 \%)$ & 1 & 9 & $10(17.85 \%)$ \\
\hline
\end{tabular}

\section{DISCUSSION}

The choice of treatment in ectopic pregnancy depends to a large on the characteristics of the women like parity, age, condition of contralateral tube, and fertility status. An ectopic first pregnancy reduces possibility of second conception leading to clinical pregnancy with in next 2 years in comparison with an initial miscarriage. ${ }^{4}$ In our study $88 \%$ underwent radical surgery and $12 \%$ conservative surgery. Radical surgery was done for the patients who had normal contralateral tube, ruptured ectopic with relatively more haemoperitonium, parous women, whereas conservative surgery like salpingectomy or milking was done for abnormal contralateral tube, nulliparous and tubal abortion cases. Thought the motive behind conservative surgery is to have intrauterine pregnancy later; by leaving repaired tube the chance of tubal block, recurrence and residual disease is possible. So the risks and benefits are not weighed so for. In our study $40 \%$ in conservative group $59.25 \%$ in radical group had intrauterine pregnancy without much significant difference. Some authors claim a subsequent live birth in only one third of the cases ${ }^{5,6}$ although higher rates have been reported. ${ }^{7-9}$ The risk of repeat ectopic pregnancy was comparable in the 2 groups, $20 \%$ in the conservative treatment group and $18.49 \%$ in the radical treatment group. This agrees with many research studies ${ }^{10}$ although some decreased rates of recurrent ectopic pregnancy have been reported with the conservative procedure. ${ }^{5,7}$ Our study showed that preexisting conditions influence fertility outcome than the type of surgery perse. Only $25 \%$ of patients who had history of subfertility had intrauterine pregnancy compare to $46.42 \%$ without subfertility history. Therefore patients with subfertility history tend to have worst outcome irrespective of surgery. Secondly those patients age $<30$ had more intrauterine pregnancies compare to $>30$ years. It is believed that fertility decreases by $9 \%$ with each year of a woman's age after 30, due to the aging effect on the ovum. $^{11}$ Thirdly patients with normal tube had better 
outcome compare to women with abnormal tube. Occurrence of repeat ectopic was more commonly seen in patients with abnormal tube compare to normal tube. Tubal pathology influences the occurrence of ectopic.

Our study was observational and had few patients which reflected the events of day to day gynecological practice and most of the patients were managed surgically. Till date only one randomized controlled study which concluded that there is no significant difference either between medical and surgical treatment or conservative and radical surgery. Once surgery is necessary, in more active ectopic pregnancies, should lead to a reconsideration of the balance between considerations of initial recovery and those of fertility preservation. ${ }^{12}$ In the treatment of tubal ectopic laparoscopic treatment remain cornerstone of the treatment. ${ }^{13}$ Laparoscopic salpingotomy has shown higher pregnancy rates compare laparotomy. ${ }^{14}$ Our study did not have laparoscopic surgeries to compare with laparotomy. Contrary to conventional wisdom the chance of subsequent intrauterine pregnancy were similar in all EP patients regardless of whether their treatment was radical or conservative. ${ }^{15}$ Medical therapy of ectopic pregnancy is appealing over surgical options for a number of reasons, including eliminating morbidity from surgery and general anesthesia, potentially less tubal damage, less cost and need for hospitalization. Some small studies have shown that tubal patency and future reproductive outcomes are significantly improved in women managed expectantly compared with those who underwent surgery. ${ }^{16,17}$

\section{CONCLUSIONS}

Subfertility, tubal pathology and age will influence on fertility outcome following ectopic pregnancy. Radical or conservative surgery does not have influence on future pregnancy outcome.

Funding: No funding sources

Conflict of interest: None declared

Ethical approval: The study was approved by the institutional ethics committee

\section{REFERENCES}

1. Job-Spira N, Bouyer J, Pouly JL, Germain E, Coste J., Aublet-Cuvelier B, et al. Fertility after ectopic pregnancy: first results of a population-based cohort study in France. Hum Reprod. 1996;11(1):99-104.

2. Bouyer J, Coste J, Shojaei T, Pouly JL, Fernandez H, Gerbaud L, et al. Risk factors for ectopic pregnancy: a comprehensive analysis based on a large casecontrol, population-based study in France. Am J Epidemiol. 2003;157:185-94.
3. Bangsgaard N, Lund CO, Ottesen B, Nilas L. Improved fertility following conservative surgical treatment of ectopic pregnancy. BJOG. 2003;110:765-70.

4. Battacharyas, McLernon DJ, Lee AJ, Battacharya S. Reproductive outcome following ectopic pregnancy register based study. PLoS Med. 2012;9(6):e1001243.

5. Decherney A, Kase N. The conservative surgical management of unruptured ectopic pregnancy clinical prospective. Obstet Gynacol. 1979;54:451-5.

6. Leach Re. Ory SJ. Modern management of ectopic pregnancy clinical prospective. J Reprod Med. 1989;34:324-38.

7. Oelsner G, Morad J, Carp H, Marshiach S, Serr DM. Reproductive performance following conservative microsurgical management of tubal pregnancy. Br J Obstet Gynaecol. 1987;94:1078-88.

8. Sherman D, Langer R, Sadovsky G, Bukovsky I, Caspi E. Improved fertility following ectopic pregnancy. Fertil Steril. 1982;37:497-502.

9. Lindblom B, Hahlin M, Lundorff P, Thornburn J. Treatment of tubal pregnancy by laparoscope guided injection of prostaglandin f2 alpha. Fertil Steril. 1990;54:404-8.

10. Clausen I. Conservative versus radical surgery for tubal pregnancy - a review. Acta Obstet Gynecol Scand. 1996;75:8-12.

11. Collins JA, Grosirguani PG. Unexplained infertility: a review of diagnosis, prognosis, treatment efficacy and management. Int $\mathbf{J}$ Gynaecol Obstet. 1992;39:267-75.

12. Herve Fernandez, Perrine Capmas, Jean Philippe Lucot, Benoit Resch, Pierre Panel, Jeanbouyer for the GROG. Fertility after ectopic pregnancy. The DEMETER randomized trial. Hum Reprod. 2013;28(5):1247-53.

13. Hajenius PJ, Mol BW, Ankun WM, van der Veen F, Bossuyt PM. Intervention for tubal ectopic pregnancy. Cochrane Database Syst Rev. 2000;(1):CD000324.

14. Fernandez H, Marchal L, Vincent Y. Fertility after radical surgery for tubal pregnancy. Fertil Steril. 1998 Oct;70(4):680-6.

15. Herve Fernandez, Amelie. Ectopic pregnancy after infertility treatment. Modern diagnosis and therapeutic strategy. Hum Reprod Update. 2004;10(6):503-13.

16. Ali Abdelhamed M. Mostfa, Hossam M. AbdelRahman. The Prognostic value of tubal patency test after medical treatment of an ectopic pregnancy. J Clin Gynecol Obstet. 2012 Oct;1(4-5):67-70.

17. Mukul LV, Teal SB. Current management of ectopic pregnancy. Obstet Gynecol Clin North Am. 2007;34(3):403-19.

DOI: $10.18203 / 2320-1770$. ijrcog20150099

Cite this article as: Veena KS, Vidyameena R, Kollipaka R. Factors influencing fertility outcome after ectopic pregnancy: a descriptive observational study. Int J Reprod Contracept Obstet Gynecol $2015 ; 4: 820-3$. 